\title{
Emergency Research: Using Exception from Informed Consent, Evaluation of Community Consultations
}

\author{
Prasanthi Govindarajan, MBBS, MAS, Neal W. Dickert, MD, PhD, Michele Meeker, RN, Natalie De Souza,
} MD, Deneil Harney, MPH, MSW, Claude J. Hemphill, MD, MAS, and Rebecca Pentz, PhD

\begin{abstract}
Background: In 1996, the U.S. Food and Drug Administration approved regulations authorizing an exception from informed consent (EFIC) for research conducted in emergency settings when obtaining prospective informed consent is not possible due to the potential subject's critical illness or injury. The regulations require that investigators conduct community consultation (CC) efforts before initiating a study and require that institutional review boards review the results of CC prior to approving a study. However, little is known about how communities view EFIC research or the CC process.

Objectives: The objective was to assess the views of CC meeting attendees regarding the CC process, their understanding and views of EFIC research relating to the specific research trial under discussion, and their level of trust in physician-investigators.

Methods: Following CC meetings at two study sites (San Francisco and Atlanta) for the Rapid Anticonvulsant Medication Prior to Arrival Trial (RAMPART), an active comparison, randomized trial of prehospital treatment for status epilepticus, the authors administered a pair of surveys to participants. One survey focused on CC experiences (CC survey) and trust in physician-investigators; the second assessed participants' understanding of EFIC and the RAMPART clinical trial design (EFIC survey).

Results: A total of 317 individuals participated in one of the two most popular types of CC meetings (group meetings and focus group sessions) at both sites. A total of 189 participants (59\%) completed the CC survey and trust questions, and $297(92 \%)$ completed the EFIC survey. Of those who completed the CC survey, 173 of 189 (92\%) were very satisfied with the meeting, and 174 of 189 (92\%) felt that they learned a lot about research at the meeting. A total of 169 of 189 participants (88\%) felt that researchers heard the community's concerns, while only 106 of $189(56 \%)$ said researchers would be willing to make changes to the study based on their concerns. Of those who completed the EFIC survey, 261 of 297 (88\%) supported the study, 207 of $297(70 \%)$ said they would agree to participate in the study, and 203 of $297(68 \%)$ reported that they would agree to consent a loved one into the study. On a recently validated scale measuring trust in physician-investigators, participants at both sites seemed to have higher levels of trust in physician-investigators than the validation study population.
\end{abstract}

Conclusions: Overall, members of these two communities expressed satisfaction with the CC session and had relatively high levels of support for the study and trust in physician-investigators.

ACADEMIC EMERGENCY MEDICINE 2013; 20:98-103 (c) 2013 by the Society for Academic Emergency Medicine

From the Department of Emergency Medicine, University of California (PG, ND), San Francisco, CA; the Division of Cardiology, Department of Medicine, Emory University (NWD), Atlanta, GA; the Department of Neurology, San Francisco General Hospital (MM, CJH), San Francisco, CA; the Department of Emergency Medicine, University of Michigan (DH), Ann Arbor, MI, and Hematology and Oncology in Ethics, Winship Cancer Institute (RP), Atlanta, GA.

Received February 14, 2012; revision received April 20, 2012; revision received and accepted April $29,2012$.

Presented at the National Association of EMS Physicians annual meeting, Phoenix, AZ; January 2010.

The primary author was funded by a career development award (1K08HS017965-01) from the Agency of Healthcare Research and Quality and the American Heart Association/American Stroke Association Western States Clinical Research Program.

The authors have no potential conflicts of interest to disclose.

A related commentary appears on page 104.

Supervising Editor: James Adams, MD.

Address for correspondence and reprints: Prasanthi Govindarajan, MBBS, MAS; e-mail: prasanthi.ramanujam@emergency.ucsf.edu. 
I nformed consent is an important ethical requirement for most research involving human subjects. However, when conducting clinical research on treatment for acute and life-threatening conditions, it is often impractical or impossible to obtain prospective consent from the patient or a surrogate. Under such circumstances, U.S. Food and Drug Administration and Department of Health and Human Services regulations allow an exception from the requirement for prospective informed consent (EFIC; 21 CFR 50.24). ${ }^{1}$ These regulations contain specific provisions regarding which studies are eligible for EFIC. They also require that investigators consult with members of the community in which the research will be conducted. The EFIC regulations define community consultation (CC) as consultation with representatives of the communities in which the clinical investigation will be conducted (geographic community) and from which the subjects will be drawn, i.e., population of potential research subjects, which is the condition-oriented community. ${ }^{2}$ However, the published guidelines on how CC should be conducted, or how input received from CC ought to be incorporated into study design or review, ${ }^{2}$ are vague.

Various methods of CC have been implemented by research teams conducting EFIC research. For example, open public forums, meetings with existing community groups, focus groups, and face-to-face and telephone surveys are all commonly employed. These methods differ greatly in size, scope, expense, and level of interaction with participants, and they likely accomplish different potential goals of CC. There remains a need to clarify the various goals of the CC process in EFIC research, develop outcome measures for those goals, and use those measures to assess the effectiveness of particular methods and identify best practices. Assessing the views of community members on the CC process is an important step in achieving these goals. ${ }^{3}$

In this study, our objectives were to assess the attitudes of CC participants toward the process of CC and EFIC. We also sought to ascertain their level of trust in medical researchers, both because promoting trust is often described as one goal of $\mathrm{CC}^{3}$ and because it is unknown whether CC participants tend to reflect the general population regarding their general attitudes toward research and researchers.

\section{METHODS}

\section{Study Design and Population}

This was a survey study to assess participant responses to CC on EFIC. The study was conducted within the Rapid Anticonvulsant Medication Prior to Arrival Trial (RAMPART), a study conducted through the Neurological Emergencies Treatment Trials (NETT) Network. ${ }^{4}$ The NETT is a multicenter network funded by the National Institute of Neurologic Disorders and Stroke to conduct clinical trials related to acute neurological illnesses. RAMPART is the first NETT trial to use EFIC and is a double-blind, randomized clinical trial to determine the efficacy of intramuscular midazolam versus intravenous lorazepam for the prehospital treatment of status epilepticus. This CC study was reviewed and approved by the institutional review boards of the study sites.
Our study was conducted by two NETT sites (San Francisco and Atlanta) during CC meetings that preceded the clinical trial. RAMPART investigators at each site identified the groups to consult with and planned the CC activities in preparation for the trial. The existing meetings at the sites targeted condition-oriented and geographic communities. Examples of geographic community meetings include town hall meetings, churches, schools, existing educational program meetings for the Hispanic population of the region, and monthly meetings for the Asian community. Individuals or family members of individuals affected by seizure, including individuals with a self-reported seizure disorder, were targeted using support of the local seizure groups and meetings were conducted at foundations for seizure patients and at substance abuse centers. One site also conducted focus groups led by a trained moderator. The focus group sessions were conducted by an external contractor, and no study personnel were involved (Table 1).

Our sample consisted of attendees over 18 years of age who attended the CC meetings and completed either or both of the study surveys. All adult CC participants were eligible for participation.

\section{Survey Content and Administration}

Study Instruments. Two survey instruments were used in this study. The first instrument (CC survey) was designed to assess the participant's experiences with the CC process, thoughts on how researchers might be likely to respond to feedback from the community, and levels of trust in physician-investigators generally (see Data Supplement S1, available as supporting information in the online version of this paper). The questions regarding trust represent a previously validated fouritem scale to measure trust in medical researchers. ${ }^{5}$ The trust scale employed Likert-scale responses ranging from 1 = strongly disagree to $5=$ strongly agree. The

Table 1

Types of CC Activities

\begin{tabular}{|c|c|c|}
\hline Overview & $\begin{array}{l}\text { Number of } \\
\text { Participants }\end{array}$ & $\begin{array}{c}\text { Type of } \\
\text { Community }\end{array}$ \\
\hline \multicolumn{3}{|l|}{ Site $1(n=137)$} \\
\hline Existing Group Meeting 1 & 21 & GC* \\
\hline Existing Group Meeting 2 & 29 & $\mathrm{CO}-\mathrm{C}^{\dagger}$ \\
\hline Existing Group Meeting 3 & 11 & $\mathrm{CO}-\mathrm{C}$ \\
\hline Existing Group Meeting 4 & 30 & $\mathrm{CO}-\mathrm{C}$ \\
\hline Existing Group Meeting 5 & 11 & \\
\hline Existing Group Meeting 6 & 7 & $\mathrm{CO}-\mathrm{C}$ \\
\hline Existing Group Meeting 7 & 7 & GC \\
\hline Existing Group Meeting 8 & 21 & $\mathrm{CO}-\mathrm{C}$ \\
\hline \multicolumn{3}{|l|}{ Site $2(n=180)$} \\
\hline Existing Group Meeting & 151 & GC \\
\hline Focus Group Meeting & 29 & $\mathrm{CO}-\mathrm{C} / \mathrm{GC}$ \\
\hline \multicolumn{3}{|c|}{$\begin{array}{l}\text { Both surveys were administered at all meetings at both sites. } \\
\mathrm{CC}=\text { community consultation; CO-C = condition-oriented } \\
\mathrm{Community}, \mathrm{GC}=\text { geographic community. } \\
{ }^{*} \mathrm{GC} \text { is defined as the region from which subjects are drawn } \\
\text { for the study } \\
+\mathrm{CO} C \text { is defined as the population with the condition that is } \\
\text { being studied using the clinical trial. In RAMPART, seizure/ } \\
\text { status epilepticus is the condition of interest. }\end{array}$} \\
\hline
\end{tabular}


trust score for the study was calculated based on the methodology described by Hall et al. ${ }^{5}$; a composite trust score by event location was calculated by adding the mean score for each item, with reverse coding for the one negatively phrased item.

The second instrument (EFIC survey) was a template designed by the Clinical Coordinating Center of the NETT Network for customization by sites for local implementation during RAMPART CC events. The template focused on eliciting participants' thoughts, feelings, and opinions about the RAMPART trial in general, and conducting RAMPART under the EFIC regulations. Specifically, level of support for the study and attitudes toward both personal and/or family enrollment in RAMPART were asked (Data Supplement S2, available as supporting information in the online version of this paper). One site used a 5-point Likert scale and the other site used a 4-point Likert scale in the survey sheet. Both surveys were available in the Spanish language for Spanish-speaking participants at the San Francisco site (Data Supplement S3, available as supporting information in the online version of this paper).

Existing Group Meetings. Surveys were distributed to CC participants by members of the study team after the conclusion of the CC meeting, which typically included a slide presentation by a member of the RAMPART study team and an opportunity for discussion. The slide presentation explained the goals and methodology of the clinical trial, including a careful explanation of randomization, as well as an overview of EFIC and its use in emergency research.

Focus Group Discussions. At one study site, four separate focus group meetings were conducted with: 1) parents of children with seizures, 2) parents of children without known seizures, 3) adults with seizures, and 4) adults without known seizures. Within each group, attempts were made to match the demographics of the group to the local population with regard to race, socioeconomic status, and sex. Focus groups were conducted by an independently contracted and trained moderator, and each session was designed to last about 1 hour. ${ }^{6}$ The investigators were involved in creating the interview guide and "training" the contractor. The moderator led the focus group discussion after an initial scripted presentation of study and EFIC information (similar to the information session at the existing meetings) designed jointly by the site investigators and the contractor. Feedback was actively solicited in the focus groups, and site investigators directly observed the session from a private room to ensure that the feedback was accurately understood and represented to the institutional review board. As was done at community meetings, study surveys were distributed to the focus group participants after completion of the focus group session.

\section{Data Analysis}

Raw data from the surveys were entered into a Microsoft Office Excel 2007 (Microsoft Corp., Redmond, WA) spreadsheet at both sites (PG and research assistants). The data sets from both sites were merged for analysis. Likert scale response categories were collapsed into agree and disagree for the 4-point scale and agree, neutral, and disagree for 5-point scales. Data were analyzed using Microsoft Office Excel 2007 and are presented as aggregate data and percentages. Themes from the focus group discussions were analyzed and summarized by the contracted moderator who provided the services and were presented as a summary report to the Atlanta site investigators. One of the authors who was not a RAMPART investigator (NWD) also directly observed all four focus groups.

\section{RESULTS}

A total of 297 (94\%) EFIC surveys and 189 (64\%) CC surveys were available for analysis. Demographic data in the central database were available for 317 participants. Overall, there was a predominance of female participants $(79 \%)$ and whites $(72 \%)$ in the focus group sessions. Compared to the community demographics, existing meetings and focus group sessions had a lower proportion of minorities (African American and Asian populations; Table 2).

The CC survey results (Table 3) showed that more than $90 \%(n=173)$ of participants agreed or strongly agreed with the statement "I was very satisfied with this CC meeting," and 92\% $(n=174)$ reported learning a lot about research from the meeting. Although $88 \%$ ( $n=166$ ) felt that researchers heard the community concerns, only $56 \%(n=106)$ of participants responded that they believed researchers would make changes if requested. It is unknown whether the responses indicate that participants did not see a need for changes or that they believed investigators would not make needed changes.

While the surveys did not assess the nature of the concerns that CC participants may have had with EFIC or the RAMPART trial, the focus groups did provide limited insights in this respect. The principal concerns mentioned among focus group participants who expressed concerns had to do with the process of randomization, the risks and benefits of receiving an unapproved drug, and the loss of decision-making autonomy associated with EFIC.

Responses by focus group participants were not significantly different than responses from existing meeting CC participants. However, the demographics of the focus group participants were different from those of the existing group meeting participants. Focus groups had a predominance of females $(79 \%)$ and whites $(72 \%)$ compared to the existing group participants $(52 \%$ females and $43 \%$ whites). Most focus group participants also reported being satisfied with the meeting $(83 \%)$ and stated that researchers heard the community concerns $(88 \%)$. As with the other population, fewer subjects $(38 \%)$ felt that researchers would make changes requested by the participants.

Responses to the questions on trust did show some variability by event, with mean scores ranging from 12.25 to 16.48 . Of note, the large event with the mean trust score of 16.48 was an event where the participants likely knew the presenter and were expected to have higher trust scores. However, mean trust scores after excluding this group did not change significantly (14.26 
Table 2

CC Meeting Participant Demographics

\begin{tabular}{|c|c|c|c|c|c|}
\hline Demographic & $\begin{array}{l}\text { Existing Meeting } \\
(n=288), n(\%)\end{array}$ & $\begin{array}{l}\text { Focus Group } \\
(n=29), n(\%)\end{array}$ & $\begin{array}{l}\text { San Francisco } \\
\text { Community, \% }\end{array}$ & $\begin{array}{c}\text { Atlanta } \\
\text { Community, \% }\end{array}$ & $\begin{array}{r}\text { Total } \\
N=317\end{array}$ \\
\hline \multicolumn{6}{|l|}{$\operatorname{Sex}^{*}$} \\
\hline Male & $116(40)$ & $6(21)$ & 51 & 50 & 122 \\
\hline Female & $150(52)$ & $23(79)$ & 49 & 50 & 173 \\
\hline \multicolumn{6}{|l|}{ Race $^{\dagger}$} \\
\hline White & $123(43)$ & $21(72)$ & 49 & 38 & 144 \\
\hline Black/African American & $67(23)$ & $6(21)$ & 6 & 54 & 73 \\
\hline Asians & $34(12)$ & $1(3)$ & 33 & 3 & 35 \\
\hline Native Hawaiian or Pacific Islander & $6(2)$ & $0(0)$ & $<1$ & $\mathrm{~N} / \mathrm{A}$ & 6 \\
\hline American Indian or Alaska Native & $11(4)$ & $0(0)$ & $<1$ & $<1$ & 11 \\
\hline More than one race & $8(3)$ & $1(3)$ & $\mathrm{N} / \mathrm{A}$ & $\mathrm{N} / \mathrm{A}$ & 9 \\
\hline Others & $12(4)$ & 1 (3) & 5 & 2 & 13 \\
\hline Not provided & $27(9)$ & $0(0)$ & N/A & $\mathrm{N} / \mathrm{A}$ & 27 \\
\hline \multicolumn{6}{|l|}{ Ethnicity ${ }^{\dagger}$} \\
\hline Hispanic/Latino & $20(7)$ & $1(3)$ & 15 & 5 & 21 \\
\hline Non-Hispanic/non-Latino & $82(28)$ & $21(72)$ & 42 & 36 & 103 \\
\hline Not reported by participants & & N/A & & & 214 \\
\hline
\end{tabular}

Table 3

Responses to CC Survey Questions ( $n=189$ )

\begin{tabular}{|c|c|}
\hline Response & Agree, $n(\%)$ \\
\hline $\begin{array}{l}\text { I was very satisfied with } \\
\text { this meeting }\end{array}$ & $173(92)$ \\
\hline $\begin{array}{l}\text { I learned a lot about research } \\
\text { at this meeting }\end{array}$ & $174(92)$ \\
\hline $\begin{array}{l}\text { I felt the researcher heard the } \\
\text { community concerns }\end{array}$ & $166(88)$ \\
\hline $\begin{array}{l}\text { I think the researchers will make } \\
\text { the changes we requested }\end{array}$ & $106(57)$ \\
\hline $\begin{array}{l}\text { I intend to help the researchers be } \\
\text { successful in this research }\end{array}$ & 149 (79) \\
\hline
\end{tabular}

Table 4

Trust Scores by Event

\begin{tabular}{|lcc|}
\hline & $\begin{array}{c}\text { Number of } \\
\text { CC Event }\end{array}$ & $\begin{array}{c}\text { Mean Trust Score } \\
\text { Participants }(n=189)\end{array}$ \\
(Sum of the Means)
\end{tabular}

Table 5

Community Views on Enrollment in the Trial Using EFIC $(n=297)$

\begin{tabular}{|c|c|}
\hline Questions & Agree, $n(\%)$ \\
\hline $\begin{array}{l}\text { Has the RAMPART study been } \\
\text { explained so that you understand } \\
\text { the risks and possible benefits? }\end{array}$ & $273(92)$ \\
\hline $\begin{array}{l}\text { Would you agree to participate in } \\
\text { this study? }\end{array}$ & $207(70)$ \\
\hline $\begin{array}{l}\text { Would you agree to consent a loved } \\
\text { one into this study? }\end{array}$ & $203(68)$ \\
\hline $\begin{array}{l}\text { Do you support this study being done in } \\
\text { your community? }\end{array}$ & $261(88)$ \\
\hline \multicolumn{2}{|c|}{$\begin{array}{l}\text { EFIC = Exception From Informed Consent; RAMPART = Rapid } \\
\text { Anticonvulsant Medication Prior to Arrival Trial. }\end{array}$} \\
\hline
\end{tabular}

vs. 14.44). In general, the totaled scores were similar between existing meeting events and focus group events. The average score for all CC participants (14.44) was greater than the national sample (12.4) in which the scale was initially validated (Table 4).

The views of the 297 participants who completed the EFIC survey are shown in Table 5. Of the group meeting participants, $88 \%(n=261)$ supported the study being done in their community, $70 \%(n=207)$ said that they would agree to participate in the study, and $68 \%$ ( $n=203$ ) said they would agree to consent for participation of a loved one in the study. Focus group participants reported similar rates of acceptance of the trial and enrollment under EFIC as was observed in the existing meeting sessions (Table 5).

\section{DISCUSSION}

As part of the CC efforts for the RAMPART trial, investigators at the two study sites participated in existing 
group meetings and conducted focus group sessions. Previous studies have reported attitudes of CC using random-digit dialing, survey distribution at large public gatherings, and public meetings. ${ }^{7-9}$ This study is the first, to our knowledge, to involve multiple sites and to compare attitudes of participants in focus groups and at meetings convened with existing community groups. Also, this is the first study, to our knowledge, to report on CC participants' level of trust in physician-investigators.

Overall, our study demonstrated a high level of support for the RAMPART trial in both communities $(88 \%$ supported the study overall). While direct comparisons of our responses with other CC studies is limited by some differences in the framing of the questions, similar results $(82 \%)$ were reported by a study using survey data from a Minnesota state fair ${ }^{9}$ to understand the community's attitudes toward the same clinical trial.

Compared with responses regarding their general support for the RAMPART study, CC participants reported slightly lower support when queried about their willingness to enroll in the study personally or to enroll a family member. This distinction has been reported in other studies of the general public and CC participants. $^{9-11}$ Notably, we found greater willingness to be enrolled personally than did Biros et al. ${ }^{9}$ in asking about the same EFIC trial (70\% vs. $45 \%)$. Some of this difference may be due to the structure of the questions. Biros et al. explicitly described enrollment using EFIC, whereas our survey only referred to willingness to participate in the RAMPART study, without a specific reference to EFIC. An alternative explanation is that different methods of CC may yield different responses regarding acceptance of EFIC and enrollment. In particular, the Biros et al. survey was administered to individuals who stopped at a booth at a state fair; ours was administered after a presentation and discussion or focus group session, contexts that may promote more education and understanding regarding the relevant study and that allow for some degree of interaction and discussion regarding concerns that may be present. These are thus very different contexts, with one likely reflecting initial public reaction and the other more considered opinions. The hypothesis that greater interactiveness and discussion may lead to higher levels of acceptance among CC participants is also at least somewhat supported by the finding that focus group participants had a slightly higher rate of acceptance of enrollment than did participants in existing group meetings. These two suggestions (that phrasing of questions and the structure of CC events may have a significant impact on the responses of CC participants) have been proposed before, ${ }^{8}$ but they are of great significance to CC investigators designing, and institutional review boards reviewing, CC plans and results. Further work is needed to understand both the utility of different CC methods and the expected responses.

While detailed analysis of the focus group sessions was not the goal of this study, the focus group sessions did provide some insights into the nature of objections to EFIC enrollment and this study. While the majority of the focus group participants supported personal enrollment as well as enrolling their loved one in the clinical trial, reasons for reluctance to participate in the clinical trial included concerns about the process of randomization (both that emergency medical services providers would not be using their clinical judgment and that subjects might receive an inferior treatment), concerns about potential side effects and interactions of the medications being evaluated, and concerns about being enrolled in a trial without being asked.

Finally, our study was the first, to our knowledge, to examine elements of trust among CC participants, which is important for several reasons. First, we add to the understanding of an often-cited goal of CC efforts: fostering trust among relevant communities. Second, our data provide knowledge on the level of trust among CC participants. This is significant since there are some concerns that CC processes may select individuals who may not reflect the general population and therefore their level of trust may not be generalizable to the relevant population. In addition, it helps to determine whether public concerns about EFIC research stem from general mistrust regarding clinical investigation, concerns about the absence of consent in EFIC research, or more specific objections to elements of proposed studies. Our results indicate that CC participants were slightly more trusting than the national sample on which the scale was validated. This at least suggests that CC participants in our study were not, in general, an abnormally trusting group; CC did not appear to select for individuals who are substantively different from the rest of the population. However, our study did not assess the effect of the CC session itself on trust, and so one focus of future efforts could be to examine this effect through the use of similar trust scales before and after CC sessions and in the context of different CC methods. Finally, the findings from the focus group sessions do suggest that specific concerns about randomization, study risks and benefits, and loss of autonomy drove concerns about enrollment and EFIC, rather than general sentiments of distrust. Since the focus groups, however, were not designed to test this hypothesis, and in-depth analysis of the focus group sessions is not the focus of this article, these findings must be interpreted primarily as hypothesisgenerating only.

\section{LIMITATIONS}

Studying CC participants, by definition, excludes individuals who do not participate in CC sessions. While the sample was demographically diverse and the level of trust seemed commensurate with the general population, we do not know the differences between our participants and those who declined participation in these events. Second, while the survey responses provided a global view of the consultants' reaction and response to the questions on EFIC and CC, investigators did not have the opportunity, outside of focus group sessions, to examine in depth the reasons for particular responses. Finally, while the focus group sessions offset some of the limitations of the survey design by providing a better understanding of the community's views on the clinical trial and EFIC, this study did not involve an in-depth qualitative analysis of these sessions. 


\section{CONCLUSIONS}

A majority of the participants in this study supported the processes of community consultation and exception from informed consent research, as well as the conduct of the RAMPART trial in their communities. Compared with other studies examining the attitudes of community consultation participants or the general public regarding exception from informed consent research, this study suggests that the method of community consultation may have an effect on the level of acceptance of exception from informed consent and personal willingness to be enrolled. Community consultation participants in this study exhibited slightly higher, but similar, levels of trust as a previously studied national sample. However, the effect of community consultation on trust in investigators and the effect of trust on attitudes toward exception from informed consent studies both warrant further evaluation

This study contributes to a growing body of literature regarding community consultation for exception from informed consent research and suggests important questions to be examined in future studies in order to best understand how to accomplish the goals of community consultation in this context. Most importantly, it suggests that it is critical to examine the effect of different methods of community consultation on the nature of feedback received. Similarly, it is important to further study the extent to which community consultation populations reflect, or do not reflect, the communities that they are intended to represent. Community consultation is not required by federal regulations for any other kind of research. Understanding its goals, methods, and limitations is crucial for the field of emergency research.

The authors acknowledge Amy Markowitz, JD, Clinical Translational Science Institute, University of California San Francisco, for her editorial assistance with the manuscript.

\section{References}

1. Department of Health and Human Services/U.S. Food and Drug Administration. Protection of Human Subjects: Informed Consent and Waiver of Informed Consent Requirements in Certain Emergency Research; Final Rules. 21 CFR part 50.24. Federal Registrar. 1996;61:51497-531.

2. Department of Health and Human Resources/U.S. Food and Drug Administration. Guidance for Institutional Review Boards, Clinical Investigators, and Sponsors. Exception from Informed Consent Requirements for Emergency Research. Draft Guidance, 2006. Available at: http://www.fda.gov/ohrms/dockets/98fr/06d-0331gdl0001.pdf. Accessed Jul 13, 2012.
3. Richardson LD, Quest TE, Birnbaum S. Communicating with communities about emergency research. Acad Emerg Med. 2005; 12:1064-70.

4. Silbergleit R, Lowenstein D, Durkalski V, Conwit R; Neurological Emergency Treatment Trials (NETT) Investigators. RAMPART (Rapid anticonvulsant Medication Prior to Arrival Trial): a double-blind randomized clinical trial of the efficacy of intramuscular midazolam versus intravenous lorazepam in the prehospital treatment of status epilepticus by paramedics. Epilepsia. 2011;52(Suppl 8):45-7.

5. Hall MA, Camacho F, Lawlor JS, Depuy V, Sugarman J, Weinfurt K. Measuring trust in medical researchers. Med Care. 2006; 44:1048-53.

6. Majority Opinion Research. Research Tools and Techniques. Available at: http://majorityopinionresearch.com/about/tools/tools.htm. Accessed Jul 13, 2012.

7. Bulger EM, Schmidt TA, Cook AJ, et al. The random dialing survey as a tool for community consultation for research involving the emergency medicine exception from informed consent. Ann Emerg Med. 2009; 53:341-50.

8. Contant C, McCullough LB, Mangus L, Robertson C, Valadka A, Brody B. Community consultation in emergency research. Crit Care Med. 2006; 34:204952.

9. Biros MH, Sargent C, Miller K. Community attitudes towards emergency research and exception from informed consent. Resuscitation. 2009; 80:1382-7.

10. Longfield JN, Morris MJ, Moran KA, Kragh JF Jr, Wolf R, Baskin TW. Community meetings for emergency research community consultation. Crit Care Med. 2008; 36:731-6.

11. McClure KB, DeIorio NM, Gunnels MD, Ochsner MJ, Biros MH, Schmidt TA. Attitudes of emergency department patients and visitors regarding emergency exception from informed consent in resuscitation research, community consultation, and public notification. Acad Emerg Med. 2003; 10:352-9.

\section{Supporting Information}

The following supporting information is available in the online version of this paper:

Data S1. Community consultation participant survey (CC survey).

Data S2. Community consultation evaluation (EFIC survey).

Data S3. Community consultation participant survey (CC survey in spanish). 